\section{BMJ Open Respiratory Research}

\title{
Prognostic indicators for in-hospital mortality in COPD with acute exacerbation in Thailand: a retrospective cohort study
}

\author{
Thotsaporn Morasert (D) , ${ }^{1}$ Methus Jantarapootirat (D) , ${ }^{1}$ Phichayut Phinyo (D) ,2 \\ Jayanton Patumanond ${ }^{2}$
}

To cite: Morasert T, Jantarapootirat M, Phinyo P, et al. Prognostic indicators for in-hospital mortality in COPD with acute exacerbation in Thailand: a retrospective cohort study. BMJ Open Resp Res 2020;7:e000488. doi:10.1136/ bmjresp-2019-000488

- Additional material is published online only. To view please visit the journal online (http://dx.doi.org/10.1136/ bmjresp-2019-000488).

Received 4 September 2019 Revised 23 April 2020 Accepted 24 April 2020
Check for updates

\section{(C) Author(s) (or their} employer(s)) 2020. Re-use permitted under CC BY-NC. No commercial re-use. See rights and permissions. Published by BMJ.

${ }^{1}$ Pulmonary and Critical care Medicine, Department of Internal Medicine, Suratthani Hospital, Surat Thani, Suratthani, Thailand ${ }^{2}$ Center for Clinical Epidemiology and Clinical Statistics, Chiang Mai University Faculty of Medicine, Chiang Mai, Thailand

Correspondence to Dr Thotsaporn Morasert; thot_kwan@hotmail.com

\section{ABSTRACT}

Background Acute exacerbation of chronic obstructive pulmonary disease (AECOPD) is a common and deteriorating event leading to in-hospital morbidity and mortality. Identification of predictors for in-hospital mortality of AECOPD patients could aid clinicians in identifying patients with a higher risk of death during their hospitalisation.

Objective To explore potential prognostic indicators associated with in-hospital mortality of AECOPD patients.

Setting General medical ward and medical intensive care unit of a university-affiliated tertiary care centre.

Methods A prognostic factor research was conducted with a retrospective cohort design. All admission records of AECOPD patients between October 2015 and September 2016 were retrieved. Stratified Cox's regression was used for the primary analysis.

Results A total of 516 admission records of 358 AECOPD patients were included in this study. The in-hospital mortality rate of the cohort was 1.9 per 100 person-day. From stratified Cox's proportional hazard regression, the predictors of in-hospital mortality were aged 80 years or more ( $\mathrm{HR}=2.16,95 \% \mathrm{Cl}: 1.26$ to $3.72, \mathrm{p}=0.005)$, respiratory failure on admission ( $\mathrm{HR}=2.50,95 \% \mathrm{Cl}: 1.12$ to $5.57, \mathrm{p}=0.025)$, body temperature more than $38^{\circ} \mathrm{C}$ $(\mathrm{HR}=2.97,95 \% \mathrm{Cl}: 1.61$ to $5.51, \mathrm{p}=0.001)$, mean arterial pressure lower than $65 \mathrm{~mm} \mathrm{Hg}(\mathrm{HR}=4.01,95 \% \mathrm{Cl}: 1.88$ to $8.60, p<0.001$ ), white blood cell count more than 15 $x 10^{9} / \mathrm{L}(\mathrm{HR}=3.51,95 \% \mathrm{Cl}: 1.90$ to $6.48, \mathrm{p}<0.001)$ and serum creatinine more than $1.5 \mathrm{mg} / \mathrm{dL}(\mathrm{HR}=2.08,95 \% \mathrm{Cl}$ : 1.17 to $3.70, p=0.013$ ).

Conclusion Six independent prognostic indicators for in-hospital mortality of AECOPD patients were identified. All of the parameters were readily available in routine practice and can be used as an aid for risk stratification of AECOPD patients.

\section{INTRODUCTION}

Chronic obstructive pulmonary disease (COPD) is a leading cause of morbidity and mortality. It was estimated to be the third leading cause of death worldwide by the year 2020. ${ }^{1}$ In Thailand, the prevalence of COPD was reported at 177 per 100000 population in
Key messages

What is the key question?

- What are the prognostic indicators for in-hospital mortality in AECOPD patients?

What is the bottom line?

- Several indicators associated with in-hospital mortality in AECOPD included those aged more than 80 years old, respiratory failure on admission, high initial body temperature $\left(\geq 38^{\circ} \mathrm{C}\right)$, low mean arterial pressure $(\leq 65 \mathrm{~mm} \mathrm{Hg})$, high white blood cell count $\left(\geq 15 \times 10^{9} / \mathrm{L}\right)$ and increased serum creatinine leve $(\geq 1.5 \mathrm{mg} / \mathrm{dL})$.

\section{Why read on?}

- The knowledge of these prognostic indicators could aid clinicians in identifying patients with a higher risk of death during their hospitalisation and thus resulting in better overall patient care and survival.

$2013,{ }^{2}$ and the prevalence of COPD was also higher in the rural $(6.8 \%)$ compared with urban $(3.7 \%)$ regions. ${ }^{3}$ Although biomass fuels and other environmental factors might contribute to COPD, especially in developing countries, ${ }^{4}$ the most common risk factor for COPD in Thailand is cigarette smoking. ${ }^{5}$

Acute exacerbation of COPD (AECOPD) is defined as an acute worsening of respiratory symptoms in COPD patients who subsequently require additional therapy. ${ }^{6}$ AECOPD considerably affects the disease progression and the deterioration of overall pulmonary function, impairs quality of life and increases the risk of further exacerbations and mortality. ${ }^{7-9}$ Prevention of the occurrence of AECOPD is, therefore, a vital goal in the management and care of patients. However, a large proportion of COPD patients still experience recurrent exacerbations, ${ }^{6}$ and approximately $30 \%$ require hospitalised care, ${ }^{710}$ which results in an even higher risk of mortality. ${ }^{11}$ 
Several prognostic factors associated with in-hospital mortality of AECOPD patients were reported and they included patients' demographics and comorbidities (age, ${ }^{10} 1213$ male sex, ${ }^{1013}$ cigarette smoking, ${ }^{14}$ low body mass index (BMI), ${ }^{13} 15$ atrial fibrillation, ${ }^{16}$ cardiac failure, ${ }^{17}$ coronary heart disease ${ }^{18}$ and stroke ${ }^{18}$ ), history and physical examination (impaired neurological status, ${ }^{10}{ }^{19}$ tachycardia $^{19}$ and lower limb oedema ${ }^{10}$ ), COPD-specific severity features (baseline dyspnoea grade, ${ }^{1020}$ low forced expiratory volume in $1 \mathrm{~s}$ (FEV1) ${ }^{13}$ cor pulmonale, ${ }^{14}$ laboratory investigation (eosinopenia, ${ }^{16}$ abnormal blood gas values, ${ }^{12}{ }^{14}$ acidaemia, hypercapnia, ${ }^{14}$ hypoxia ${ }^{14}$ and higher blood urea nitrogen $\left.(\mathrm{BUN})^{19}\right)$, hypoalbuminemia $\left.{ }^{13}\right)$, acute kidney injury ${ }^{21}$ and pneumonia. ${ }^{81320}$

However, the effect and significance of each predictor on mortality varied across different studies. ${ }^{1522}$ This study aims to explore the prognostic indicators for in-hospital mortality in AECOPD patients admitted to a tertiary care centre in Thailand, a developing country.

\section{METHODS}

\section{Study design and setting}

We conducted prognostic factor research with retrospective cohort design in a university-affiliated tertiary care centre, Suratthani Hospital, Thailand.

\section{Study participants}

All admission records of AECOPD patients aged 40 years or more, admitted to the general medical wards or medical intensive care unit (MICU) of Suratthani Hospital between October 2015 and September 2016, were included. The diagnosis of AECOPD was based on the 'principal diagnosis' by the International Statistical Classification of Diseases and Related Health Problems 10 (ICD-10) codes J44.0, J44.1 and J44.9 in the discharge summary. All admission charts were externally audited and AECOPD diagnosis was confirmed by a pulmonologist. If any admission was diagnosed and summarised to 'pneumonia' as the principal cause of hospitalisation and 'COPD' as comorbidity, they would not be included in this study. However, patients with AECOPD as a principal diagnosis (major cause of admission) and had consolidation in chest radiography were eligible for our study. They were recognised as 'pneumonic exacerbation' in some studies. ${ }^{8}$ Patients with spirometry results inconsistent with COPD, FEV1/forced vital capacity (FVC) ratio of more than 0.7 and other active pulmonary disease (acute respiratory distress syndrome, lung cancer or acute pulmonary embolism) were excluded. The unit of observation in this study was each hospitalised admission for each COPD patient. Thus, the data were, therefore, collected in multiple records for patients with recurrent admissions during the study period.
Data collection

Patients' demographic and clinical data associated with the investigation and treatment of each admission were extracted from medical records. Demographic and baseline characteristic data included gender, age, BMI, smoking status, comorbidities diagnosed before the index admission, the severity of COPD evaluated by spirometry (the closest result to the index admission), current inhaled controller medications and the history of influenza vaccination. The number of COPD-related events in the previous year, including both hospitalised visits and emergency department visits, were also collected. Clinical parameters including initial vital signs (body temperature (BT), heart rate, systolic blood pressure (SBP), diastolic blood pressure (DBP), mean arterial pressure (MAP) and respiratory rate (RR)), admission to MICU, the presence of respiratory failure requiring intubation, initial chest radiography interpreted by attending physicians, laboratory investigations within the first 24 hours of hospitalisation and therapeutic profile were retrieved from each admission record. All patient admission records were separated into two groups: non-survived admissions and survived admissions based on the survival status of the patient.

\section{Prognostic factors threshold}

All the prognostic factors thresholds were chosen based on previous literature and clinical experiences: (1) age $\geq$ 80 years; advance age, ${ }^{23}$ (2) $\mathrm{BT} \geq 38^{\circ} \mathrm{C}$; represent fever, ${ }^{24}$ (3) MAP $<65 \mathrm{~mm} \mathrm{Hg}$; international sepsis guideline, ${ }^{25}$ (4) serum creatinine $(\mathrm{SCr}) \geq 1.5 \mathrm{mg} / \mathrm{dL}$; presence of initial renal insufficiency. Although the ${ }^{26}$ Kidney Disease: Improving Global Outcomes (KDIGO) on acute kidney injury (AKI) suggested the increase in $\mathrm{SCr}(>1.5$ times of baseline) rather than single $\mathrm{SCr}$ value, we recognised that many COPD patients did not have baseline SCr information on evaluation. Thus, an assumption was made that most previously stable COPD patients should have a wellpreserved renal function or $\mathrm{SCr}$ less than or equal to 1 , (5) white blood cell (WBC) count $\geq 15 \times 10^{9} / \mathrm{L}$; increase the chance of having a bacterial infection, ${ }^{27}$ (6) neutrophil count $\geq 9 \times 10^{9} / \mathrm{L}$, eosinophil count $<50 / \mathrm{mm}^{3}$, haemoglobin $<120 \mathrm{~g} / \mathrm{L}, \mathrm{BUN}>20 \mathrm{mg} / \mathrm{dL}$; DECAF score for $\mathrm{AECOPD}^{16}$, (7) serum sodium $<135 \mathrm{mmol} / \mathrm{L}$ and serum chloride $<95 \mathrm{mmol} / \mathrm{L}$; represent hyponatremia and hypochloremia.

\section{Patient and public involvement}

Patients and the public were not involved in the design, conduct, reporting or funding of this research.

\section{Statistical analysis}

All statistical analyses were performed using Stata Statistical Software: Release V.16 (StataCorp LLC). Prior to statistical modelling, clinical characteristics and associated parameters were compared between survived and 
non-survived admissions with descriptive statistics. For normally distributed data, mean and SD were used for description, and Student's t-test was used for comparison. For skewed data, median and IQR were used for description, and the Mann-Whitney test was used for comparison. Categorical data were presented as frequency and percentage. The comparison of categorical data was made using the exact probability test. Variables with more than $20 \%$ missing were excluded from statistical modelling. All analyses were two-sided with a p value $<0.05$ as a critical value for statistical significance. The continuous data were dichotomised based on threshold values as described earlier. For multiple time data with marginal risk sets, Cox's proportional hazard $(\mathrm{PH})$ regression was used. The model was stratified by order of admission to allow the hazard function to vary on each visit (sequence or order-specific). ${ }^{28}{ }^{29}$ Radiographic consolidation and admission to the MICU on admission were included as a confounder in the model for adjustment of probable pneumonia status. As the main objective of this study was exploratory, only HRs of the potential predictors were presented in the results. Cluster variance based on an individual patient was used to account for within-patient correlation. We assessed for $\mathrm{PH}$ assumption via statistical testing using Schoenfeld residuals. HR and its 95\% CI were estimated for each of the potential prognostic indicators.

As the main focus was on the parameters of each admission, length of hospital stay and the duration of mechanical ventilation were omitted from the analysis. A univariable stratified Cox's regression was modelled for each potential predictor reported in prior studies. Predictors with $p$ value $<0.1$ from the univariable model were included in the final multivariable stratified Cox's model, where multivariable or adjusted HRs were reported. Multiple imputations was done for variables with missing data of less than $20 \%$. As the imputed model showed no significant difference from the non-imputed model, we chose to report the complete-case analysis. Sensitivity analysis with the single-record approach, where readmission visits were excluded, was performed to investigate the robustness of the primary results, which was derived from the multiple-record approach with stratified Cox's regression.

\section{RESULTS}

A total of 527 admissions of AECOPD were retrieved. Of this number, 11 admissions with inconsistent spirometry results, FEV1/FVC $>0.7$, were excluded. Finally, 516 admission records of 358 patients were included for analysis. During the study period, 67 patients died, and 291 survived the admission. The cumulative in-hospital mortality of the cohort was $18.7 \%(67 / 358)$, while the rate of in-hospital mortality was 1.9 per 100 person-day. Fifty-five patients $(10.7 \%)$ were admitted to the MICU, and the mortality was $32.7 \%$. The baseline clinical characteristics of AECOPD patients within the study cohort $(\mathrm{n}=358)$ and missing data were shown in table 1 . The use of inhaled controller medications in survived and non-survived admissions ( $\mathrm{n}=516)$ was shown in online supplementary table 1 . The patients were predominantly men $(86.3 \%)$ with the mean age of 74 years $( \pm$ SD 11.1$)$. There was a higher proportion of patients aged $\geq 80$ years in the non-survived group compared with the survived group $(52.2 \%$ vs $34.1 \%, \mathrm{p}=0.006)$. Ninety-four per cent of the patients were either current or past smokers. Only $22.9 \%$ of the patients had spirometry results. The mean of FEV1/FVC was $0.50( \pm \mathrm{SD} 0.11)$. Influenza vaccine was administered in $23(6.4 \%)$ patients before hospitalisation.

Several clinical parameters and initial laboratory investigations revealed significant differences that included BT, SBP, DBP, MAP, presence of respiratory failure, radiographic consolidation, serum sodium, serum chloride, BUN, SCr, serum albumin, haemoglobin, WBC count, neutrophil count, eosinophil count and hypoglycaemia (table 2). Besides, the median duration of mechanical ventilation and the median length of hospital stay were significantly longer in non-survived admissions than survived admissions.

Overall, $90.7 \%$ of admissions were treated with antibiotic agents. Ceftriaxone $(51.0 \%)$ and clarithromycin $(42.6 \%)$ were the most prescribed drugs. Only the prescription of clarithromycin during admission was significantly different between those who did not survive and those who survived (29.9\% vs $44.5 \%, \mathrm{p}=0.025)$ (online supplementary table 2 ).

The potential prognostic variables were selected based on both previously reported factors and factors with significant univariable testing. Patients aged $\geq 80$ years old, respiratory failure requiring intubation, $\mathrm{BT} \geq 38^{\circ} \mathrm{C}$, MAP $<65 \mathrm{~mm} \mathrm{Hg}$, WBC count $\geq 15 \times 10^{9} / \mathrm{L}$, neutrophil count $\geq 9 \times 10^{9} / \mathrm{L}$, eosinophil count $<0.05 \times 10^{9} / \mathrm{L}$, haemoglobin $<120 \mathrm{~g} / \mathrm{L}, \mathrm{SCr} \geq 1.5 \mathrm{mg} / \mathrm{dL}, \mathrm{BUN}>20 \mathrm{mg} /$ $\mathrm{dL}$, serum sodium $<135 \mathrm{mmol} / \mathrm{L}$ and serum chloride $<95$ $\mathrm{mmol} / \mathrm{L}$ were individually included in univariable analysis (table 3). According to the analysis plan, the arterial blood gas results, serum albumin and glucose values were excluded from the analysis due to more than $20 \%$ missing data. On multivariable stratified Cox's PH regression, the predictors of in-hospital mortality of AECOPD patients were those aged $\geq 80$ years old $(\mathrm{HR}=2.16,95 \% \mathrm{CI}$ : 1.26 to $3.72, \mathrm{p}=0.005$ ), had respiratory failure requiring intubation on admission (HR=2.50, 95\% CI: 1.12 to 5.57 , $\mathrm{p}=0.025)$, had high initial $\mathrm{BT} \geq 38^{\circ} \mathrm{C}(\mathrm{HR}=2.97,95 \%$ CI: 1.61 to 5.51, $\mathrm{p}=0.001)$, had $\mathrm{MAP}<65 \mathrm{~mm} \mathrm{Hg}(\mathrm{HR}=4.01$, $95 \%$ CI: 1.88 to $8.60, \mathrm{p}<0.001)$, had WBC count $\geq 15 \times$ $10^{9} / \mathrm{L} \quad(\mathrm{HR}=3.51,95 \% \mathrm{CI}: 1.90$ to $6.48, \mathrm{p}<0.001)$ and had $\mathrm{SCr} \geq 1.5 \mathrm{mg} / \mathrm{dL} \quad(\mathrm{HR}=2.08,95 \%$ CI: 1.17 to 3.70 , $\mathrm{p}=0.013)$ (table 3).

The result of the sensitivity analysis is shown in online supplementary table 3. All the estimated values (HRs), both in terms of direction and magnitude, were consistent between the multiple-record cohort and the singlerecord cohort (excluded readmission visits). The full 
Table 1 Baseline clinical characteristics of COPD patients with acute exacerbation within the study cohort $(n=358$ patients)

\begin{tabular}{|c|c|c|c|}
\hline \multirow{2}{*}{$\begin{array}{l}\text { Characteristics } \\
\text { Male }(n, \%)\end{array}$} & \multirow{2}{*}{$\begin{array}{l}\text { Missing data } \\
\text { n (\%) } \\
0(0)\end{array}$} & \multicolumn{2}{|c|}{$\begin{array}{l}\text { AECOPD patients } \\
(\mathrm{n}=358)\end{array}$} \\
\hline & & 309 & -86.3 \\
\hline Age $\geq 80$ years $(n, \%)$ & $0(0)$ & 131 & -36.6 \\
\hline $\begin{array}{l}\text { Age, years, mean } \\
( \pm S D)\end{array}$ & $0(0)$ & 74 & \pm 11.1 \\
\hline
\end{tabular}

$\begin{array}{lccc}\begin{array}{l}\text { Body mass index, } \\ \mathrm{kg} / \mathrm{m}^{2}, \text { mean }( \pm \mathrm{SD})\end{array} & 171(47.8) & 20.4 & \pm 4.2 \\ \begin{array}{l}\text { Smoking status } \\ \text { Never smoker }(\mathrm{n},\end{array} & 0(0) & 20 & -5.6 \\ \%) & & \\ \text { Ex-smoker }(\mathrm{n}, \%) & 292 & -81.6 \\ \begin{array}{l}\text { Active smoker }(\mathrm{n}, \\ \%)\end{array} & 46 & -12.9\end{array}$

\begin{tabular}{|c|c|c|c|}
\hline $\begin{array}{l}\text { Underlying diseases } \\
(n, \%)\end{array}$ & & & \\
\hline Present (any) & $0(0)$ & 296 & -82.7 \\
\hline Hypertension & $0(0)$ & 145 & -40.5 \\
\hline Diabetes mellitus & $0(0)$ & 44 & -12.3 \\
\hline Dyslipidemia & $0(0)$ & 48 & -13.4 \\
\hline $\begin{array}{l}\text { Ischaemic heart } \\
\text { disease }\end{array}$ & $0(0)$ & 36 & -10.1 \\
\hline Atrial fibrillation & $0(0)$ & 20 & -5.6 \\
\hline $\begin{array}{l}\text { Left ventricular } \\
\text { dysfunction }\end{array}$ & $0(0)$ & 6 & -1.7 \\
\hline $\begin{array}{l}\text { Chronic kidney } \\
\text { disease }\end{array}$ & $0(0)$ & 27 & -7.5 \\
\hline $\begin{array}{l}\text { Cerebrovascular } \\
\text { disease }\end{array}$ & $0(0)$ & 27 & -7.5 \\
\hline COPD status & & & \\
\hline Spirometry done & $0(0)$ & 82 & -22.9 \\
\hline
\end{tabular}

\begin{tabular}{|c|c|c|c|}
\hline $\begin{array}{l}\text { FEV1, \% } \\
\text { predicted, median } \\
\text { (IQR) }\end{array}$ & $276(77.1)$ & 38 & $\begin{array}{l}29.0 \text { to } \\
57.0\end{array}$ \\
\hline $\begin{array}{l}\text { FVC, \% predicted, } \\
\text { median (IQR) }\end{array}$ & 277 (77.4) & 64 & $\begin{array}{l}51.0 \text { to } \\
84.0\end{array}$ \\
\hline $\begin{array}{l}\text { FEV1/FVC ratio, } \\
\text { mean }( \pm S D)\end{array}$ & $276(77.1)$ & 0.5 & \pm 0.1 \\
\hline
\end{tabular}

GOLD severity of

airflow limitation $(\mathrm{n}$,

$\%)$

\begin{tabular}{|c|c|c|c|}
\hline $\begin{array}{l}\text { I: FEV1 } \geq 80 \% \\
\text { predicted }\end{array}$ & $276(77.1)$ & 6 & -1.7 \\
\hline $\begin{array}{l}\text { II: FEV1 50-79\% } \\
\text { predicted }\end{array}$ & & 20 & -5.6 \\
\hline $\begin{array}{l}\text { III: FEV1 } 30- \\
49 \% \text { predicted }\end{array}$ & & 33 & -9.2 \\
\hline
\end{tabular}

Continued

\begin{tabular}{|c|c|c|c|}
\hline Characteristics & $\begin{array}{l}\text { Missing data } \\
\text { n (\%) }\end{array}$ & $\begin{array}{l}\text { AEC } \\
(n=3\end{array}$ & patients \\
\hline $\begin{array}{l}\text { IV: FEV1 <30\% } \\
\text { predicted }\end{array}$ & & 23 & -6.4 \\
\hline $\begin{array}{l}\text { Long-term oxygen } \\
\text { therapy, }(\mathrm{n}, \%)\end{array}$ & $0(0)$ & 26 & -7.3 \\
\hline $\begin{array}{l}\text { Cor pulmonale (n, } \\
\%)\end{array}$ & $0(0)$ & 12 & -3.4 \\
\hline \multicolumn{4}{|l|}{$\begin{array}{l}\text { Number of events in } \\
\text { previous year }\end{array}$} \\
\hline $\begin{array}{l}\text { Hospitalisation, } \\
\text { median (IQR) }\end{array}$ & $25(7.0)$ & 0 & 0 to 1 \\
\hline $\begin{array}{l}\text { ED visit, median } \\
(\mathrm{IQR})\end{array}$ & 37 (10.3) & 0 & 0 to 2 \\
\hline Influenza vaccination & $0(0)$ & 23 & -6.4 \\
\hline
\end{tabular}

AECOPD, Acute exacerbation of chronic obstructive pulmonary disease; COPD, chronic obstructive pulmonary disease; ED, emergency department; FEV1, forced expiratory volume in $1 \mathrm{~s}$; FVC, forced vital capacity.

multiple-record data that were analysed with stratified Cox's regression revealed higher statistical power and precision with narrower CIs. Therefore, the primary analysis was valid and robust to changing of assumption.

\section{DISCUSSION}

In this study, six independent predictors of in-hospital mortality of AECOPD patients were identified. They were aged 80 years or more and had respiratory failure requiring intubation on arrival, BT higher than $38^{\circ} \mathrm{C}$, MAP lower than $65 \mathrm{~mm} \mathrm{Hg}$, WBC count more than $15 \mathrm{x}$ $10^{9} / \mathrm{L}$ and SCr more than $1.5 \mathrm{mg} / \mathrm{dL}$. These factors could prognosticate mortality during admission of AECOPD patients regardless of pneumonic status and whether the patients were admitted to the MICU or general medical ward on admission, as these factors were adjusted in the final regression model.

Previous studies reported a varying range of in-hospital mortality from $2 \%$ (mixed urban and rural hospital) ${ }^{19}$ to $29 \%$ (only intensive care units (ICUs)). ${ }^{15}$ The cumulative in-hospital mortality in this study was $18.7 \%$. Interestingly, ICU mortality (33\%) in our study was similar to the overall cumulative ICU mortality (29\%) in a systemic review and meta-analysis. ${ }^{15}$ Marked differences in shortterm mortality between pneumonic $(12.1 \%)$ and nonpneumonic $(8.3 \%)$ acute exacerbation patients were reported in one study. ${ }^{10}$ Our cohort had a higher proportion of pneumonic exacerbation from chest radiography $(51.2 \%)$ and a higher rate of respiratory failure on admission $(68.8 \%)$ than those of studies that reported a lower incidence of death during the hospitalised period. ${ }^{81020}$

For patients' demographic data, aged patients and the presence of comorbidities had been widely reported as significant prognostic factors for in-hospital mortality. 
Table 2 Dynamic clinical parameters during survived and non-survived admissions with acute exacerbation of chronic obstructive pulmonary disease ( $n=516$ admissions)

\begin{tabular}{|c|c|c|c|c|c|c|}
\hline \multirow{2}{*}{$\begin{array}{l}\text { Clinical parameters } \\
\text { Initial vital signs }\end{array}$} & \multirow[t]{2}{*}{$\begin{array}{l}\text { Missing data, } \\
\text { n (\%) }\end{array}$} & \multicolumn{2}{|c|}{$\begin{array}{l}\text { Non-survived admissions } \\
(\mathrm{n}=67)\end{array}$} & \multicolumn{2}{|c|}{$\begin{array}{l}\text { Survived admissions } \\
(\mathrm{n}=449)\end{array}$} & \multirow[t]{2}{*}{$P$ value } \\
\hline & & & & & & \\
\hline $\mathrm{BT},{ }^{\circ} \mathrm{C}$, median (IQR) & $1(0.2)$ & 37.2 & 37 to 38 & 37 & 36.7 to 37.4 & 0.001 \\
\hline HR, per minute, median (IQR) & $0(0)$ & 100 & 88 to 120 & 102 & 88 to 118 & 0.615 \\
\hline SBP, mm Hg, mean $( \pm S D)$ & $1(0.2)$ & 117.7 & \pm 29.0 & 136.4 & \pm 25.1 & $<0.001$ \\
\hline $\mathrm{DBP}, \mathrm{mm} \mathrm{Hg}$, mean $( \pm \mathrm{SD})$ & $1(0.2)$ & 73.7 & \pm 18.4 & 80.9 & \pm 14.9 & $<0.001$ \\
\hline MAP, mm Hg, mean $( \pm \mathrm{SD})$ & $1(0.2)$ & 88.4 & \pm 20.5 & 99.4 & \pm 16.7 & $<0.001$ \\
\hline $\mathrm{RR}$, per minute, mean $( \pm \mathrm{SD})$ & $0(0)$ & 26.2 & \pm 5.1 & 25.4 & \pm 5.3 & 0.253 \\
\hline Admission to MICU (n, \%) & $0(0)$ & 18 & -26.9 & 37 & -8.2 & $<0.001$ \\
\hline Respiratory failure on admission (n, \%) & $0(0)$ & 61 & -91 & 294 & -65.5 & $<0.001$ \\
\hline Radiographic consolidation (n, \%) & $0(0)$ & 50 & -74.6 & 214 & -47.7 & $<0.001$ \\
\hline \multicolumn{7}{|l|}{ Laboratory investigations } \\
\hline $\mathrm{pH}$, mean $( \pm \mathrm{SD})$ & $420(81.4)$ & 7.31 & \pm 0.21 & 7.37 & \pm 0.13 & 0.144 \\
\hline $\mathrm{PaO}_{2}, \mathrm{~mm} \mathrm{Hg}$, median (IQR) & $425(82.4)$ & 130 & 75.1 to 262 & 151 & 92.2 to 216 & 0.363 \\
\hline $\mathrm{PaCO}_{2}, \mathrm{~mm} \mathrm{Hg}$, median (IQR) & $420(81.4)$ & 37.2 & 26.9 to 43.4 & 37.1 & 26.9 to 47.2 & 0.791 \\
\hline Sodium, mmol/L, mean $( \pm \mathrm{SD})$ & $11(2.1)$ & 136.6 & \pm 8.0 & 138.6 & \pm 4.4 & 0.003 \\
\hline Potassium, mmol/L, mean $( \pm \mathrm{SD})$ & $11(2.1)$ & 4.1 & \pm 0.8 & 4 & \pm 0.6 & 0.121 \\
\hline Chloride, $\mathrm{mmol} / \mathrm{L}$, mean $( \pm \mathrm{SD})$ & $12(2.3)$ & 93.6 & \pm 8.7 & 97.6 & \pm 5.6 & $<0.001$ \\
\hline Bicarbonate, $\mathrm{mmol} / \mathrm{L}$, mean $( \pm \mathrm{SD})$ & $11(2.1)$ & 24.9 & \pm 7.9 & 24.3 & \pm 5.0 & 0.36 \\
\hline Blood urea nitrogen, mg/dL, median (IQR) & $11(2.1)$ & 21 & 15 to 32 & 15 & 11 to 21 & $<0.001$ \\
\hline Serum creatinine, mg/dL, median (IQR) & $9(1.7)$ & 1.1 & 0.8 to 1.5 & 0.9 & 0.8 to 1.2 & 0.03 \\
\hline Serum albumin, g/dL, mean $( \pm S D)$ & $193(37.4)$ & 3.4 & 2.9 to 3.7 & 3.9 & 3.5 to 4.2 & $<0.001$ \\
\hline Haemoglobin, g/L, mean $( \pm S D)$ & $8(1.6)$ & 121 & 107 to 132 & 130 & 117 to 140 & 0.004 \\
\hline WBC count, $\times 10^{9} / \mathrm{L}$, median (IQR) & $8(1.6)$ & 15.1 & 10.4 to 19.4 & 12.6 & 9.4 to 16.3 & 0.022 \\
\hline Neutrophil count, $\times 10^{9} / \mathrm{L}$ median (IQR) & $0(0)$ & 13.76 & 8.35 to 17.1 & 10.25 & 6.8 to 14.45 & 0.014 \\
\hline Eosinophil count, $\times 10^{9} / \mathrm{L}$, median (IQR) & $0(0)$ & 0.01 & 0 to 0.07 & 0.05 & 0 to 0.29 & $<0.001$ \\
\hline Platelet count, $\times 10^{9 / L}$, median (IQR) & $8(1.6)$ & 232.5 & 158.0 to 328.0 & 244.0 & 193.0 to 302.0 & 0.569 \\
\hline Peak glucose, mg/dL, median (IQR) & $195(37.8)$ & 214 & 160 to 272 & 192 & 151 to 247 & 0.102 \\
\hline Hypoglycaemia (glucose <55 mg/dL) & $213(41.3)$ & 15 & -27.3 & 15 & -6.1 & $<0.001$ \\
\hline $\begin{array}{l}\text { Mechanical ventilator duration, days, median } \\
\text { (IQR) }\end{array}$ & $0(0)$ & 7 & 3 to 18 & 2 & 0 to 4 & $<0.001$ \\
\hline Length of hospital stay, days, median (IQR) & $0(0)$ & 7 & 2 to 20 & 4 & 2 to 6 & $<0.001$ \\
\hline
\end{tabular}

BT, body temperature; HR, heart rate; SBP, systolic blood pressure; DBP, diastolic blood pressure; MAP, mean arterial pressure; RR, respiratory rate; MICU, medical intensive care unit; WBC, white blood cell.

Increasing age $\mathrm{e}^{101330}$ or patients aged more than 75 years ${ }^{12}$ were significantly associated with death during hospitalisation, as the patients' FEV1 declines at a more accelerated rate in older COPD patients than younger ones. ${ }^{31}$ Comorbidities were not significantly different among survived and non-survived admissions, which was similar to one study reported that no association between the number of comorbidities and mortality in AECOPD patients. ${ }^{32}$ This finding was in contrast to the result of another study, which showed that the higher number of comorbidity from the Deyo-adapted Charlson Index was a significant predictive factor of in-hospital mortality. ${ }^{30} \mathrm{~A}$ vast majority of patients in this study were men, which was similar to the previous report in North-eastern Thailand in $2014 .{ }^{33}$ The explanation was probably due to a higher proportion of smokers in men than women. Also, the misdiagnosis of COPD as asthma in female patients due to gender bias was common. ${ }^{34}$

Acute respiratory failure on admission and requirement of mechanical ventilation were consistently reported to be essential prognostic factors for both in-hospital mortality and postdischarge mortality. ${ }^{35}$ Acidotic respiratory failure reflects the severity of the exacerbation. This condition is modifiable if it is early identified, via blood gas analysis, and properly managed. Non-invasive ventilation had been proven to be an immediate intervention that can effectively reduce mortality in patients with acute acidotic respiratory failure due to exacerbation of COPD.$^{35}$ Nonetheless, this non-invasive approach was not widely available in our limited-resource setting. 
Table 3 Prognostic factors associated with in-hospital mortality among hospitalised AECOPD patients by univariable and multivariable stratified Cox's PH regression analysis with variance correction

\begin{tabular}{|c|c|c|c|c|}
\hline \multirow[b]{2}{*}{ Prognostic factors } & \multicolumn{2}{|l|}{ Univariable model } & \multicolumn{2}{|l|}{ Multivariable model } \\
\hline & Crude HR $(95 \% \mathrm{Cl})$ & $P$ value & Adjusted HR (95\% Cl) & P value \\
\hline Age $\geq 80$ years & 1.78 (1.05 to 3.03$)$ & 0.032 & 2.16 (1.26 to 3.72$)$ & 0.005 \\
\hline Respiratory failure (intubation) & 2.26 (0.99 to 5.14$)$ & 0.052 & 2.50 (1.12 to 5.57$)$ & 0.025 \\
\hline $\mathrm{BT} \geq 38.0^{\circ} \mathrm{C}$ & 2.12 (1.21 to 3.69$)$ & 0.008 & 2.97 (1.61 to 5.51$)$ & 0.001 \\
\hline $\mathrm{MAP}<65 \mathrm{~mm} \mathrm{Hg}$ & $5.38(2.44$ to 11.87$)$ & $<0.001$ & 4.01 (1.88 to 8.60$)$ & $<0.001$ \\
\hline WBC count $\geq 15 \times 10^{9} / \mathrm{L}$ & 2.39 (1.42 to 4.01$)$ & 0.001 & 3.51 (1.90 to 6.48$)$ & $<0.001$ \\
\hline Neutrophil count $\geq 9 \times 10^{9} / \mathrm{L}$ & $1.36(0.80$ to 2.34$)$ & 0.258 & - & - \\
\hline Eosinophil count $<0.05 \times 10^{9} / \mathrm{L}$ & 1.63 (0.95 to 2.80$)$ & 0.077 & 1.61 (0.82 to 3.18$)$ & 0.167 \\
\hline Haemoglobin $<120 \mathrm{~g} / \mathrm{L}$ & $0.90(0.52$ to 1.56$)$ & 0.714 & - & - \\
\hline Serum creatinine $\geq 1.5 \mathrm{mg} / \mathrm{dL}$ & 2.19 (1.19 to 4.04$)$ & 0.012 & 2.08 (1.17 to 3.70$)$ & 0.013 \\
\hline Blood urea nitrogen $>20 \mathrm{mg} / \mathrm{dL}$ & 1.74 (0.99 to 3.04$)$ & 0.053 & 1.55 (0.74 to 3.23$)$ & 0.248 \\
\hline Serum sodium $<135 \mathrm{mmol} / \mathrm{L}$ & 1.21 (0.67 to 2.18$)$ & 0.520 & - & - \\
\hline Serum chloride $<95 \mathrm{mmol} / \mathrm{L}$ & 1.38 (0.82 to 2.31$)$ & 0.222 & - & - \\
\hline
\end{tabular}

The models were adjusted for radiographic consolidation status and admission to the medical intensive care unit on admission.

AECOPD, acute exacerbation of chronic obstructive pulmonary disease; BT, body temperature; MAP, mean arterial pressure; WBC, white blood cell.

Most of the patients still required invasive endotracheal intubation for mechanical ventilation and even carried a higher risk of in-hospital mortality. In Thailand, not all patients with acute respiratory failure could be initially admitted to the MICU because of ICU overcrowdedness. Most patients were treated and mechanically ventilated in general medical wards. For this reason, the multivariable model was adjusted for the admission status of each patient to properly explore for risk factors that were independent of the place that the patients were admitted.

Pneumonia, or the presence of radiographic consolidation, was considered as another factor of poor outcomes in AECOPD patients. ${ }^{80}$ However, chest radiography was commonly known as an insensitive test for identifying early pneumonia. ${ }^{36}$ Thus, the presence of pneumonia in AECOPD patients should not rely entirely on radiographic consolidation but other possible clinical signs of pneumonia, such as higher BT and increased WBC count from initial complete blood count. In this study, both BT higher than $38^{\circ} \mathrm{C}$ and WBC count more than $15 \times 10^{9} / \mathrm{L}$ were included in the multivariable analysis. They yielded a significant result for the prediction of in-hospital mortality independent of consolidation status. Previous studies supported that higher neutrophil counts $^{37}$ and pneumonia ${ }^{813}$ can be used as predictors for in-hospital mortality. In contrast, one integrative review of low-quality studies reported contradicting results that BT and WBC variables could not predict intermediateterm mortality in a specific group of AECOPD patients who require ICU admission. ${ }^{22}$

On initial univariable analysis, our study demonstrated that all of the blood pressure components were significantly lower in non-survived admissions compared with those who survived. In statistical analysis, only the MAP was included in the regression model due to the highest OR and the presence of collinearity among the blood pressure components. MAP lower than $65 \mathrm{~mm} \mathrm{Hg}$ was identified as the strongest independent predictor of in-hospital mortality $(\mathrm{HR}=4)$, which was supported by a previous study of AECOPD requiring ICU admission. ${ }^{38}$ The cause of hypotension in AECOPD could be either cardiogenic or non-cardiogenic in origin. In patients with high pulmonary pressure, right-sided heart failure or cor pulmonale is common and considered a terminal event for COPD patients. Identifying the exact aetiology of hypotension could provide the proper preventive strategy or early management; however, this was beyond the scope of our study.

Several laboratory parameters were explored for their potential prognostic properties in this study, but only the rising of SCr or the presence of acute kidney injury was confirmed as a significant predictor for in-hospital mortality, in concordance with the previous report. ${ }^{21}$ Although the final multivariable analysis did not fulfil other prior hypotheses of those laboratory parameters, some of our observations were supported by past studies such as hypoalbuminemia, ${ }^{16}{ }^{39}$ hyponatremia, ${ }^{39}$ hypochloremia, ${ }^{40}$ eosinopenia ${ }^{16}$ and anaemia. ${ }^{41}$ Hyponatremia is a common predictive marker of mortality and morbidity of AECOPD patients, although the effect found in our study was modest and non-significant. ${ }^{40}$

Generally, all admitted AECOPD patients are administered with systemic corticosteroids during their admission in our setting, both intravenous and oral route. Prehospitalised use of inhaled corticosteroids was identified in about $65 \%$ of all admission records (online supplementary table 1). Both the use of systemic corticosteroids in the recent admission ${ }^{42}$ and prehospitalised inhaled corticosteroid $^{4344}$ might explain the low level of eosinophil in this study. Recently, one study had reported an increased risk of sepsis after the use of oral corticosteroids, but not for inhaled corticosteroid. ${ }^{45}$ This sepsis risk could sustain 
for approximately 5 months after corticosteroid exposure. As our prognostic factors for AECOPD mortality are overlapped with features associated with sepsis, recent use of systemic corticosteroids could likely confound our results. Therefore, in our analysis, low eosinophil count, a probable marker of steroid use, was incorporated in the multivariable model, thereby adjusting its effect when interpreting others. Our Cox's analysis was stratified by order of admission, which allows the comparison of prognostic factors among patient visits with similar baseline risk for in-hospital mortality.

Our study reported a set of independent prognostic factors of in-hospital mortality for AECOPD patients admitting in a tertiary care centre in Thailand, where the burden and spectrum of disease were substantially different from those of previous research. These factors could aid clinicians in risk stratification for optimal management. For example, an elderly patient with the presence of organ dysfunctions (respiratory failure, shock or renal insufficiency) should be considered as a high-risk patient who required continuous monitoring and admission to an ICU. For patients with fever or leucocytosis, we should suspect systemic infection or sepsis. Prompt septic workup and adequate empirical antimicrobial treatment are crucial.

The strength of our study was gained from multiplerecord data collection and multiple failure-time survival analysis of the primary outcome; these allow us to quantify marginal risk for the study population with the preservation of statistical power. Another critical point was the adjustment of radiographic consolidation and admission to the MICU within the analysis model, which enable the consideration of each factor independent of pulmonary consolidation status and differential severity of the patient. The included predictors were also objective and routinely available on admission. This study carried some limitations. First, the data collection was retrospective. Data on some clinically relevant factors such as clinical dyspnoea scale and home oxygen therapy status were unavailable. Second, only a small proportion of patients had spirometry results prior to the index admissions $(22.5 \%)$ and had blood samples taken for blood gas analysis (18.6\%). As this study excluded the patients with inconsistent spirometry results from the analysis, the presence of selection bias was possible. However, this represents real-life clinical practice, as spirometry results were available only in $19-50 \%$ of COPD patients, ${ }^{46-48}$ and only 11 patients $(3.1 \%)$ were excluded from this study based on the spirometry result. Finally, our study result was based on a single tertiary referral centre. Thus, this limited the generalisability to non-tertiary care centres.

Although we recognised that spirometry was essential for diagnosis and provided useful information about the severity of stable COPD, ${ }^{6}$ in real life the spirometry services were not sufficiently done and properly documented. Interestingly, these problems seemed to be global. The National Committee for Quality Assurance of the USA showed that spirometry was infrequently used and had been done only in one-third of the patients. ${ }^{49}$ Another data from a large
Welsh COPD Primary Care Audit also reported that only $19 \%$ of COPD patients had been verified with the 'gold standard' post-bronchodilator FEV1/FVC. ${ }^{48}$ Currently, in Thailand, COPD patients were diagnosed by physicians based on symptoms, signs, risk factors (advanced age and smoking status) and chest radiographic results that were compatible with COPD (diffuse pulmonary hyperinflation). In this study, the diagnosis of COPD was based primarily on the ICD-10 codes, as there was a study in the UK that supported the use of specific diagnostic codes to accurately identify COPD patients. ${ }^{50}$ The COPD definition used in this study was, therefore, pragmatic rather than deterministic. We believed that our estimated set of indicators could be suitably generalised to settings where COPD diagnosis relies mainly on clinical profiles.

It was clearly identified that there was a very low number of hospitalised AECOPD patients who were properly evaluated with arterial blood gas within the first 24 hours. There were some explanations for this clinical defect. First, arterial blood gas analysis would not generally be done in AECOPD patients who were not intubated. Second, the imbalance in the number of physicians and patient workload impeded the chance that the patients would receive arterial puncture within the first 24 hours. As we aimed to explore for prognostic indicators that were readily available in all patients on admissions, arterial blood gas was not included in the model.

In conclusion, the prognostic indicators for in-hospital mortality in AECOPD patients admitting to a tertiary care centre in Thailand included patients aged 80 years or more, and those who had the following characteristics: acute respiratory failure on admission, BT higher than $38^{\circ} \mathrm{C}$, MAP lower than $65 \mathrm{~mm} \mathrm{Hg}$, initial $\mathrm{WBC}$ count more than $15 \times 10^{9} / \mathrm{L}$ and SCr more than $1.5 \mathrm{mg} / \mathrm{dL}$.

Acknowledgements The authors thank V Boonsarngsuk for his advice to improve the manuscript.

Contributors We confirm that all the authors have contributed to this paper in the following way: conception and design of the article: TM, MJ, PP and JP. Data collection: MJ. Data analysis and interpretation: TM, PP and JP. Drafting the article: TM and MJ. Critical revision of the article: TM, PP and JP. Final approval of the version to be published: TM, MJ, PP and JP.

Funding Medical education centre of Suratthani Hospital, Thailand.

Competing interests None declared.

Patient and public involvement Patients and/or the public were not involved in the design, or conduct, or reporting, or dissemination plans of this research.

Patient consent for publication Not required.

Ethics approval The study protocol was approved by the ethical committee of Suratthani Hospital, Thailand. (Approval ID: 25/2562)

Provenance and peer review Not commissioned; externally peer reviewed.

Data availability statement Data are available upon reasonable request. All data relevant to the study are included in the article or uploaded as supplementary information. Data are available upon reasonable request (email: thot_kwan@ hotmail.com).

Open access This is an open access article distributed in accordance with the Creative Commons Attribution Non Commercial (CC BY-NC 4.0) license, which permits others to distribute, remix, adapt, build upon this work noncommercially, and license their derivative works on different terms, provided the original work is properly cited, appropriate credit is given, any changes made indicated, and the use is non-commercial. See: http://creativecommons.org/ licenses/by-nc/4.0/. 
ORCID iDs

Thotsaporn Morasert http://orcid.org/0000-0002-3353-2033

Methus Jantarapootirat http://orcid.org/0000-0001-8918-3744

Phichayut Phinyo http://orcid.org/0000-0002-8543-6254

\section{REFERENCES}

1 Lozano R, Naghavi M, Foreman K, et al. Global and regional mortality from 235 causes of death for 20 age groups in 1990 and 2010: a systematic analysis for the global burden of disease study 2010. Lancet 2012;380:2095-128.

2 Bundhamcharoen K, Odton P, Phulkerd S, et al. Burden of disease in Thailand: changes in health gap between 1999 and 2004. BMC Public Health 2011;11:53.

3 Pothirat C, Chaiwong W, Phetsuk N, et al. A comparative study of COPD burden between urban vs rural communities in northern Thailand. Int J Chron Obstruct Pulmon Dis 2015;10:1035-42.

4 Barnes PJ, Burney PGJ, Silverman EK, et al. Chronic obstructive pulmonary disease. Nat Rev Dis Primers 2015;1:15076-76.

5 Patanavanich R, Aekplakorn W, Suriyawongpaisal P. Trend analysis of smoking-attributable hospitalizations in Thailand, 2007-2014. Tob Induc Dis 2018;16:52.

6 Vogelmeier CF, Criner GJ, Martinez FJ, et al. Global strategy for the diagnosis, management, and prevention of chronic obstructive lung disease 2017 report. gold executive summary. Am J Respir Crit Care Med 2017;195:557-82.

7 Müllerova H, Maselli DJ, Locantore N, et al. Hospitalized exacerbations of COPD: risk factors and outcomes in the eclipse cohort. Chest 2015;147::999-1007.

8 Søgaard M, Madsen M, Løkke A, et al. Incidence and outcomes of patients hospitalized with COPD exacerbation with and without pneumonia. Int J Chron Obstruct Pulmon Dis 2016;11:455-65.

9 Fernandes L, Vadala R, Gulati N, et al. Quality of life at discharge from hospital following acute exacerbation of COPD is much worse even if length of stay is short. Eur Respir J 2016;48:PA3667.

10 Roche N, Zureik M, Soussan D, et al. Predictors of outcomes in COPD exacerbation cases presenting to the emergency department. Eur Respir J 2008;32:953-61.

11 Hillas G, Perlikos F, Tzanakis N. Acute exacerbation of COPD: is it the "stroke of the lungs"? Int J Chron Obstruct Pulmon Dis 2016;11:1579-86.

12 Bustamante-Fermosel A, De Miguel-Yanes JM, Duffort-Falcó $\mathrm{M}$, et al. Mortality-related factors after hospitalization for acute exacerbation of chronic obstructive pulmonary disease: the burden of clinical features. Am J Emerg Med 2007;25:515-22.

13 Sakamoto Y, Yamauchi Y, Yasunaga H, et al. Development of a nomogram for predicting in-hospital mortality of patients with exacerbation of chronic obstructive pulmonary disease. Int $J$ Chron Obstruct Pulmon Dis 2017;12:1605-11.

14 Steer J, Gibson GJ, Bourke SC. Predicting outcomes following hospitalization for acute exacerbations of COPD. QJM 2010;103:817-29.

15 Singanayagam A, Schembri S, Chalmers JD. Predictors of mortality in hospitalized adults with acute exacerbation of chronic obstructive pulmonary disease. Ann Am Thorac Soc 2013;10:81-9.

16 Steer J, Gibson J, Bourke SC. The DECAF score: predicting hospital mortality in exacerbations of chronic obstructive pulmonary disease. Thorax 2012;67:970-6.

$17 \mathrm{Li} \mathrm{H}$, Zeng Z, Cheng J, et al. Prognostic role of NT-proBNP for inhospital and 1-year mortality in patients with acute exacerbations of COPD. Int J Chron Obstruct Pulmon Dis 2020;15:57-67.

18 Roca B, Almagro P, López F, et al. Factors associated with mortality in patients with exacerbation of chronic obstructive pulmonary disease hospitalized in general medicine departments. Intern Emerg Med 2011;6:47-54.

19 Tabak YP, Sun X, Johannes RS, et al. Mortality and need for mechanical ventilation in acute exacerbations of chronic obstructive pulmonary disease: development and validation of a simple risk score. Arch Intern Med 2009;169:1595-602.

20 Steer J, Norman EM, Afolabi OA, et al. Dyspnoea severity and pneumonia as predictors of in-hospital mortality and early readmission in acute exacerbations of COPD. Thorax 2012;67:117-21

21 Fabbian F, De Giorgi A, Manfredini F, et al. Impact of renal dysfunction on in-hospital mortality of patients with severe chronic obstructive pulmonary disease: a single-center Italian study. Int Urol Nephrol 2016;48:1121-7.

22 Messer B, Griffiths J, Baudouin SV. The prognostic variables predictive of mortality in patients with an exacerbation of COPD admitted to the ICU: an integrative review. QJM 2012;105:115-26.
23 Stone RA, Lowe D, Potter JM, et al. Managing patients with COPD exacerbation: does age matter? Age Ageing 2012;41:461-8.

24 Small E, Clements CM. Defining fever: likelihood of infection diagnosis as a function of body temperature in the emergency department. Crit Care 2014;18:P42.

25 Dellinger RP, Levy MM, Rhodes A, et al. Surviving sepsis campaign. Crit Care Med 2013;41:580-637.

26 Khwaja A. KDIGO clinical practice guidelines for acute kidney injury. Nephron Clin Pract 2012;120:c179-84.

27 Moran GJ, Talan DA, Abrahamian FM. Diagnosis and management of pneumonia in the emergency department. Infect Dis Clin North Am 2008;22:53-72.

28 Prentice RL, Williams BJ, Peterson AV. On the regression analysis of multivariate failure time data. Biometrika 1981;68:373-9.

29 Westbury LD, Syddall HE, Simmonds SJ, et al. Identification of risk factors for hospital admission using multiple-failure survival models: a toolkit for researchers. BMC Med Res Methodol 2016;16:46.

30 Patil SP, Krishnan JA, Lechtzin N, et al. In-hospital mortality following acute exacerbations of chronic obstructive pulmonary disease. Arch Intern Med 2003;163:1180-6.

31 Kim SJ, Lee J, Park YS, et al. Age-related annual decline of lung function in patients with COPD. Int J Chron Obstruct Pulmon Dis 2016;11:51-60.

32 Connors AF, Dawson NV, Thomas C, et al. Outcomes following acute exacerbation of severe chronic obstructive lung disease. The support Investigators (study to understand prognoses and preferences for outcomes and risks of treatments). Am J Respir Crit Care Med 1996;154:959-67.

33 Wipa R. Precipitating causes and outcomes of chronic obstructive pulmonary disease exacerbation at a tertiary care center in northeast Thailand 2014;8:229-36.

34 Chapman KR, Tashkin DP, Pye DJ. Gender bias in the diagnosis of COPD. Chest 2001;119:1691-5.

35 Hartl S, Lopez-Campos JL, Pozo-Rodriguez F, et al. Risk of death and readmission of hospital-admitted COPD exacerbations: European COPD audit. Eur Respir J 2016;47:113-21.

36 Waterer GW. The diagnosis of community-acquired pneumonia. do we need to take a big step backward? Am J Respir Crit Care Med 2015;192:912-3.

37 Yao C, Liu X, Tang Z. Prognostic role of neutrophil-lymphocyte ratio and platelet-lymphocyte ratio for hospital mortality in patients with AECOPD. Int J Chron Obstruct Pulmon Dis 2017;12:2285-90.

38 Chok L, Nopakoon N, Elvira U. Factors affecting mortality in patients with COPD exacerbations requiring ICU admission. The southwest respiratory and critical care Chronicles, 2013.

$39 \mathrm{Kumar} \mathrm{H}$, Choubey S. Predictors of mortality in patients of acute exacerbation of chronic obstructive pulmonary disease: a prospective observational study. Indian J Respir Care 2018;7:77-82.

40 Chalela R, González-García JG, Chillarón JJ, et al. Impact of hyponatremia on mortality and morbidity in patients with COPD exacerbations. Respir Med 2016;117:237-42.

41 Ittyachen AM, Krishnamoorthy S, Bhatt AN, et al. Predictors of outcome in patients admitted with acute exacerbation of chronic obstructive pulmonary disease in a rural tertiary care center. $J$ Family Med Prim Care 2016;5:411-5.

42 Bafadhel M, McKenna S, Terry S, et al. Blood eosinophils to direct corticosteroid treatment of exacerbations of chronic obstructive pulmonary disease: a randomized placebo-controlled trial. Am J Respir Crit Care Med 2012;186:48-55.

43 Kreindler JL, Watkins ML, Lettis S, et al. Effect of inhaled corticosteroids on blood eosinophil count in steroid-naïve patients with COPD. BMJ Open Respir Res 2016;3:e000151-e51.

44 Evans PM, O'Connor BJ, Fuller RW, et al. Effect of inhaled corticosteroids on peripheral blood eosinophil counts and density profiles in asthma. J Allergy Clin Immunol 1993;91:643-50.

45 Ernst P, Coulombe J, Brassard P, et al. The risk of sepsis with inhaled and oral corticosteroids in patients with COPD. COPD 2017;14:137-42

46 Guerriero M, Caminati M, Viegi G, et al. COPD prevalence in a northeastern Italian general population. Respir Med 2015;109:1040-7.

47 Thorington P, Rios M, Avila G, et al. Prevalence of chronic obstructive pulmonary disease among stable chronic disease subjects in primary care in Trinidad, West Indies. $J$ Thorac Dis 2011;3:177-82

48 Fisk M, McMillan V, Brown J, et al. Inaccurate diagnosis of COPD: the Welsh national COPD audit. Br J Gen Pract 2019;69:e1-7.

49 Han MK, Kim MG, Mardon R, et al. Spirometry utilization for COPD: how do we measure up? Chest 2007;132:403-9.

50 Quint JK, Müllerova H, DiSantostefano RL, et al. Validation of chronic obstructive pulmonary disease recording in the clinical practice research Datalink (CPRD-GOLD). BMJ Open 2014;4:e005540. 